University of Zurich

Department of Economics

Working Paper Series

ISSN 1664-7041 (print)

ISSN 1664-705X (online)

Working Paper No. 276

\title{
Unemployment Insurance and the Labor Market
}

Josef Zweimüller

January 2018 


\title{
Unemployment Insurance and the Labor Market*
}

\author{
Josef Zweimüller, University of Zurich
}

November 2, 2017

\begin{abstract}
The existing literature assumes that unemployment insurance (UI) affects the labor market through the job finding rate of eligible workers. I argue that this focus is too narrow. I show evidence for UI effects through three other margins: (i) search externalities; (ii) takeup of other welfare state programs; and (iii) job separations. This suggests that the analysis of optimal UI should take a more comprehensive view of how UI affects the labor market.
\end{abstract}

Keywords: Unemployment insurance, extended benefits, unemployment duration, unemployment inflow, layoffs, disability insurance, optimal benefits.

JEL Codes: J65, J63, J64.

*Address: University of Zurich, CH-8000 Zurich, Switzerland; email josef.zweimueller@econ.uzh.ch. This paper was written for the Adam Smith Lecture at EALE 2017, St.Gallen, Switzerland. I want to thank the organizers for inviting me to give this lecture and for the opportunity to present my work in front of this great audience. The research discussed here would not have happened without the energy and enthusiasm of my co-authors. First and foremost, I am indebted to my long-term collaborator Rafael Lalive, who provided invaluable input for this research. With him I started working on the universe of the Austrian social security data (ASSD) in the late 1990s, a data set that many other researchers are using now. Special thanks go to Stefan Staubli with whom I have enjoyed working over the last years and whose expertise and work attitude were of tremendous help in all our projects. The research discussed here benefitted from the energetic input of Camille Landais, who initiated the market externality project. I am indebted to Lukas Inderbitzin who co-authored the paper on program substitution. The paper on UI and job separations is work in progress and I have the pleasure to work with Simon Jäger and Benjamin Schoefer on this project. Over the years, I could rely on the support of engaged and talented research assistants. Particular thanks go to Andreas Kettemann and Philippe Ruh, who were extremely helpful over the last years and who provided decisive input for the empirical evidence presented here. Thanks also to Damian Osterwalder and Dominik Egloff for putting together the tables and graphs of the paper. I also thank Andreas Steinhauer and Andreas Haller for comments on an earlier version of this paper and Johanna Posch for checking the final version. 


\section{Introduction}

Since the Great Recession of 2008/2009, unemployment insurance (UI) and its impact on labor market outcomes ranks again among the hot topics, both in policy debates and in academic research. An important reason for the renewed interest is the debate on extended unemployment benefits in the US during the Great Recession. During 2008-2011 the maximum duration of UI benefits were extended to a hitherto unkown extent, with many states granting a maximum of 99 weeks UI benefit duration. These expansions, which were eventually rolled back in 2012 and 2013, initiated a hot political debate about their usefulness. For instance, Robert Barro (2010) entitled his provocative Wall Street Journal op-ed "The folly of subsidizing unemployment", and concluded that, in the absence of extended UI benefits, US unemployment would never have exceeded 7 percent, when it actually peaked at 10 percent. Paul Krugman (NYT 2013), on the other hand, argues that extending UI benefits in bad times contributes as little to the increase in unemployment, as the increase of a speed limit can contribute to the resolution of a traffic jam. In recessions, there is a lack of jobs. Making the unemployed more desparate will not induce firms to hire more workers.

UI is one of the most important welfare state programs. Almost all industrialized countries established UI systems after WWI or in response to the Great Depression. Many developing countries have recently - or are about to - set up such a system. In Europe, many countries expanded UI generosity during the post-war boom of the 1960s and early 1970s. As European unemployment started to rise above US levels in the 1980s, many writers - most prominently Ljungqvist and Sargent $(1998,2008)$ - pointed to excessive UI generosity as a possible explanation. High UI benefits make unemployed workers reluctant to take jobs, slow down the reallocation of labor and create "Eurosclerosis", low productivity growth and high unemployment. Diagnoses along these lines called for a reduction in UI generosity as an important element of the "structural reforms" to improve labor market flexibility. A substantial body of empirical research evaluating these UI policies has emerged since then, which has improved our knowledge of the quantitative impact of UI policy parameters on unemployment durations.

Recent work in labor (and public) economics has made substantial progress in better understanding the impact of unemployment insurance on the labor market, as documented in a recent survey by Schmieder and von Wachter (2016). Empirical work has come up with convincing designs to estimate the causal impact of UI parameters on the duration of unemployment (and other post-unemployment outcomes). On the theoretical side, Chetty (2006) showed that the old Baily (1978) optimal-UI formula is much more generally applicable than previously thought; and that it helps to make better sense of our empirical estimates. Baily's (1978) formula can be stated as

$$
\frac{u^{\prime}(b)-u^{\prime}(w-\tau)}{u^{\prime}(w-\tau)}=\eta_{b}^{D},
$$

where $u^{\prime}(c)$ is marginal utility when consumption is $c, w-\tau$ is the net wage, $b$ is the UI benefit, and $\eta_{b}^{D}$ is the elasticity of unemployment duration $D$ with respect to (balanced-budget increases of) $b$. It is this elasticity, which is estimated in a typical UI study. The above formula captures the most 
simple case when workers don't save, hence during employment $c=w$ and during unemployment $c=b$. The formula is very intuitive: in the absence of moral hazard, when $\eta_{b}^{D}=0$, it is socially optimal to fully ensure workers, i.e. to set $b=w-\tau$. The higher is $\eta_{b}^{D}$ (and the lower the degree of risk aversion, captured by $u^{\prime}(c)$ ), the less generous is optimal UI.

This approach had a huge impact on the literature. Any new UI study providing a "causal" estimate of $\eta_{b}^{D}$ uses the Baily formula to make welfare statements. With a functional-form assumption on $u^{\prime}($.), the (local) optimality of UI generosity ( $b$ relative to $w-\tau$ ) can be evaluated: if the required degree of risk aversion is unplausibly high (low), the system under consideration is too generous (too restrictive).

In this lecture, I argue that the Baily-Chetty approach is too narrow. The reason is that the formula captures only one channel through which UI affects the labor market: the reduced search effort by unemployed workers. While this channel is undoubtedly important, also other margins respond to UI parameters and these responses may be quantitatively relevant. Not taking them into account may lead to a biased assessment of the social optimality of an existing UI system. In other words, a clean causal estimate of the duration elasticity $\eta_{b}^{D}$ is not enough to evaluate the social optimality of a UI system. ${ }^{1}$ Three such channels will be discussed in this lecture:

1. Market externalities (and general equilibrium responses) of UI

2. UI and other welfare state programs

3. UI and job separations

In what follows I aim to shed light on the above channels by drawing on the work that my coauthors and I have produced in previous and ongoing projects. These results indicate that the above margins are indeed quantitatively relevant. However, they should be considered as an illustration as their external validity is not clear and needs to be discussed. At the end of the lecture, I will put these results into perspective and will draw some general conclusions.

\section{Market externalities of UI extensions}

The chances of an unemployed worker to find a new job do not only depend on the worker's search effort but also on labor market conditions. The generosity of UI affects these conditions. On the one hand, a more generous UI system improves unemployed workers' outside opportunities and puts an upward pressure on wages in new jobs. Firms become more reluctant to open vacancies making it harder to find a new job. On the other hand, a more generous UI system induces workers to search less hard, thereby reducing competition for a limited number of vacancies. When all other unemployed workers search less hard, it becomes easier for me to find a new job.

\footnotetext{
${ }^{1}$ The other key parameters of the Baily-Chetty formula will not be studied in this paper. One important strand of the literature has looked at the relative importance of liquidity and moral hazard, see Chetty (2008), Card, Chetty and Weber (2007) and Landais (2015). Essentially, this approach compares job losers with and without liquid assets to better understand the consumption smoothing benefits of UI. Another approach, starting with Gruber (1997), looks directly at changes in consumer expenditures follwing a job loss and how the generosity of UI affects th response in expenditures. For recent contributions, see Kroft and Notwidigdo (2016) and Ganong and Noel (2017).
} 
Micro versus macro effects of UI. These differential labor market reponses are captured in Figures 1 and 2. (The exposition follows Michaillat (2012).) On the horizontal axis, we measure as usual - labor supply and labor demand. On the vertical axis, we measure labor market tightness $\theta$ (= open vacancies per unit of aggregate search). Labor supply and labor demand curves are drawn for a given wage rate and a given search intensity of the unemployed.

Labor supply is increasing in $\theta$. For a given search intensity of unemployed workers, a higher $\theta$ makes it is easier to find a new job. Importantly, higher UI generosity reduces unemployed workers' search intensity and shifts the labor supply curve to the left. ${ }^{2}$ The slope of the labor demand curve is not a priori clear and depends on further assumptions. Figure 1 captures the prediction of a standard search- and matching model a la Diamond-Mortensen-Pissarides (DMP). In the DMP framework, wages are flexible and worker productivity is constant. This implies a flat labor demand curve at $\theta_{0}$, which is pinned down by the zero profit condition for posting a vacancy. An increase in UI generosity puts an upward pressure on wages and reduces the incentive to post vacancies. This shifts the labor demand curve downward. In the new equilibrium tightness falls to $\theta_{1}$ and employment falls to $E_{2}$. It is easy to see that a clean causal (micro) estimate of the effect of UI on the job finding rate - comparing workers with different UI generosity but identical labor market conditions - predicts a smaller employment reduction to $E_{1}$, thus underestimating the labor market response of UI.

\section{Figure 1}

A different model is presented in Figure 2. Here it is assumed that wages are rigid and the marginal product of labor is falling. This corresponds to the case of "job rationing" studied in Michaillat (2012). ${ }^{3}$ Under these assumptions, the labor demand curve slopes downward. When tightness is low, filling a vacancy is less costly and firms are willing to employ more workers. Just like before, the labor supply curve shifts to the left. However, due to the assumption of wage rigidity, the labor demand curve remains unaffected. The new labor market equilibrium is associated with lower employment $E_{2}$, but with higher tighness $\theta_{2}$.

\section{Figure 2}

The two models generate different predictions about the relative size of micro and macro responses. The DMP model predicts that equilibrium tightness will fall. In that case, the micro effect falls short of the macro effect. The micro effect fails to capture the wage externality which exacerbates the negative effect of UI on employment. In contrast, the job rationing model predicts that equilibrium tightness will increase. In that case, the micro effect exceeds the macro effect. More generous UI induces the unemployed to search less hard for a job, thereby reducing competition for

\footnotetext{
${ }^{2} \theta$ determines the job finding rate per unit of search, $f(\theta)$. The worker's job finding rate is $e f(\theta)$. The shift of the labor supply curve occurs, because higher UI generosity reduces search effort $e$, at any given level of $\theta$.

${ }^{3}$ Michaillat (2012) argues that jobs are "rationed" in the sense that, even when tightness goes to zero (so that vacancies are filled immediately and no cost of vacancy posting accrue), worker productivity at full employment may fall short of the (rigid) wage. In such a situation there is unemployment even in the complete absence of frictions.
} 
new jobs. The micro effect does not capture this search externality which mitigates the negative effect of UI on employment.

Empirically, we can observe the individual job finding rates, $e \times f(\theta)$, but we usually cannot separately observe search effort $e$ and the job finding rate per unit of search $f(\theta) .{ }^{4}$ To identify market externalities, we need both a treated and a non-treated labor market, and variation in treatment status across worker within the treated market. Let us index by $T$ and $N$ the treated and non-treated labor market, respectively. Assume the treated labor market consists of eligible and non-eligible workers, indexed by $t$ and $n$, with population shares $p$ and $1-p$, respectively. Workers of the two groups are perfect substitutes in production and firms do not discriminate between them. The two groups differ in some characteristic that allows UI authorities to assign a UI extension to group $t$ but not to group $n$. Denote, respectively, by $e_{t}$ and $e_{n}$ the search effort in case a worker of group $t$ and $n$ gets unemployed. Since extended UI will induce workers to search less hard for a new job, we have $e_{t}<e_{n}$. Equilibrium tightness is then $\theta_{T}=v_{T} /\left(p e_{t} u_{t T}+(1-p) e_{n} u_{n T}\right)$, where $v_{T}$ is the number of vacancies posted by firms and $u_{t T}$ and $u_{n T}$ are the number of unemployed workers in each group. Moreover, if $p$ is close to unity, $\theta_{T} \approx v_{T} / e_{t} u_{t T}$, and equilibrium tightness is close to the one that would emerge if all workers in the labor market were treated.

How does this compare to a situation where the UI extension for group $t$ is not implemented? In that case, all unemployed workers will exert search effort $e_{n}$, hence equilibrium tightness in the non-treated labor market is $\theta_{N}=v_{N} /\left(e_{n} u_{N}\right)$, where $v_{N}$ and $u_{N}$ are the (endogenous) stocks of vacancies and unemployed workers when neither group $t$ nor to group $n$ are granted extended benefits. (In that case, the distinction between workers of group $t$ and $n$ becomes irrelevant.)

This simple framework allows us to identify macro effect, micro effect and externality. Empirically, we observe the job finding rates of eligible and non-eligible job losers in the treated region, $e_{t} f\left(\theta_{T}\right)$ and $e_{n} f\left(\theta_{T}\right)$; and the job finding rate of job losers in the control regions, $e_{n} f\left(\theta_{N}\right)$. This suggests the following decomposition

$$
\underbrace{e_{t} f\left(\theta_{T}\right)-e_{n} f\left(\theta_{N}\right)}_{\text {MACRO effect }}=\underbrace{\left[e_{t}-e_{n}\right] \times f\left(\theta_{T}\right)}_{\text {micro effect }}+\underbrace{e_{n} \times\left[f\left(\theta_{T}\right)-f\left(\theta_{N}\right)\right]}_{\text {externality }}
$$

where the macro effect is identified from comparing eligible workers in treated regions to workers in control regions; the externality from comparing ineligible workers in treated regions to workers in control regions; and the micro effect from comparing eligible workers to non-eligible workers in treated regions.

The Austrian Regional Extended Benefit Program. The Austrian Regional Extended Benefit Program (REBP) provides us with an empirical design, which mimics the identification strategy sketched above (Lalive, Landais and Zweimüller 2015). The program granted extended UI benefit in some regions, but did not implement extended UI in the rest of the country. Moreover, within

\footnotetext{
${ }^{4}$ In what follows, we assume that search effort depends only on $b$ but not on $\theta$. As emphasized by Shimer (2004) labor market participation and measures of search intensity do not vary strongly over the business cycle, hence this assumption seems reasonable.
} 
the treated region some workers were eligible, while others were not. This allows us to decompose observed job finding rates along the above identification framework.

Of course, the above interpretation is only valid, if treated and control regions were initially identical. They were not. In fact, the program was initiated because treated regions suffered from structural economic problems. Many plants in these regions belonged to the state-owned industries (mostly iron and steel), which faced a major crisis in the 1980s. Adverse demand shocks on international markets together with low productivity of the state-owned plants generated high financial losses covered by taxpayers' money. By the mid 1980s the government came to the conclusion that this policy could no longer be pursued. Restructuring plans were set up, unproductive plants were closed, and overstaffed plants were downsized. Because the concerned industries were strongly concentrated in certain regions of the country, the Austrian government implemented the REBP to protect older workers against economic hardships associated with the restructuring policies. Moreover, the program was not only confinded to workers previously employed in the steel industry but was available to all unemployed workers in the treated region. The REBP extended the maximum duration of UI benefits from 52 weeks to 209 (!) weeks. The eligibility criteria were the following:

- age 50 or older at the start of the UI spell,

- continuous work history (15 years of contributions to the UI system in the past 25 years),

- residence in one of 28 (out of 100) labor market districts for at least 6 months,

- unemployment spell started in June 1988 or later (including spells in progress in June 1988).

The program was in place from June 1988 until July 1993. Spells starting before August 1993 were still eligible to extended UI, meaning that the REBP was phased out gradually, with workers eligible to the REBP in the unemployment pool up until July $1998 .^{5}$

\section{Figure 3}

In sum, there are plenty of reasons why treated and control regions were not identical. Most importantly, job losers from the steel industry were confronted with a substantially worse labor market than other workers. This is why we remove steel workers from the sample. Even workers outside the steel industry may differ in local labor market conditions due to local negative demand spillovers. Different from the ideal experiment, the regions are not isolated (and observations not independent from one another). Finally, regions differ in other dimensions such as industry

\footnotetext{
${ }^{5}$ Moroever, in 6 of the originally 28 treated regions, the program was already terminated with a 1992 reform. In these districts, labor market conditions turned out not worse than non-treated regions, so that a continuation of the program was not justified. Figure 3 shows the REBP communities in (communities with blue or dark-blue shading) are all located on a contiguous area in the Eastern and Central parts of Austria. The 1992 reform left all claims in progress unaffected. For new entrants, the reform abolished the benefit extension in 6 of the originally 28 regions. It also tightened eligibility criteria, as individuals had to be not only residents, but also previously employed in a REBP region. In the figure, the dark-blue shaded areas are communities belonging to those 22 treated regions with continuous treatment form June 1988 to July 1993, while the light-blue shaded areas are those 6 treated regions where the program was abloshed in December 1991.
} 
structure and workforce composition, that may bias a regional comparison of otherwise similar workers. When interpreting the evidence we have to keep this in mind. I will come back to some of these caveats below.

Data and empirical evidence. In the empirical analysis, we use linked data from the universe of the Austrian secial security database (ASSD) and the Austrian unemployment register (AMS). We use all unemployment entrants aged 45-54 during the years 1980-2009, which includes both preand post-treatment periods. Besides unemployment entrants from the iron and steel industries, we also remove female unemployment entrants, because they were subject to different retirement rules. The final sample consists of more than 260,000 unemployment spells.

Using the data described above we first compare eligible workers in treated regions to comparable workers in control regions. In the ideal experiment this contrast identifies the macro effect of extended UI. Panel A of Figure 4 plots the difference in unemployment durations between the two groups by start date of the unemployment spell. The vertical axis measures the difference in the average duration of unemployment (in weeks) of job losers in treated regions compared to control regions. The figure indicates huge differences during the period of regional UI extensions. ${ }^{6}$ This is not surprising given the high treatment intensity (maximum UI duration extended from 1 to 4 years). The figure also indicates that no regional differences existed, neither before the program nor after its termination. This suggests that the contrast is unlikely contaminated by differential longrun trends. Nevertheless, durations do increase slightly before and do not disappear immediately after the program, which could be due to temporarily worse labor market conditions in the treated labor market during the treatment period.

\section{Figure 4}

Let us now look at the contrast of particular interest here, ineligible workers in treated regions versus comparable workers in control regions. This identifies the market externality. Panel B of Figure 4 clearly shows that non-eligible workers in treated regions find jobs more quickly than comparable workers in control regions. This means that the market externality is negative and the micro effect of extended UI exceeds the macro-effect. The evidence is inconsistent with the prediction of the DMP model which emphasizes the wage externality. The evidence is in line with the job rationing model and indicates that search externalities are the dominant force.

It is also interesting to observe the dynamics of the externality over time. It takes some time until the externality is built up and it only gradually disappears after the program is abolished. Because eligibility is tied to the date of unemployment entry, workers entering immediately before program termination can still be on extended UI until four years later (and therefore trigger UI externalities even though the newly unemployed are no longer eligible to the REBP). This conjecture is line with the evidence: regional differences for non-eligible workers become gradually weaker and disappear after four years.

\footnotetext{
${ }^{6}$ The first paper documenting the effect of the REBP on unemployment durations is Winter-Ebmer (1998). Later papers include Lalive and Zweimüller (2004a,b) and Lalive (2008).
} 
As mentioned above, an obvious caveat threatening identification are differential labor market conditions between regions. While we removed steel workers, one might argue that in regions with a strong steel sector there may be local demand spillovers which harm employment prospects also for workers from other industries. Notice, however, that in the absence of such adverse demand conditions non-eligible workers in treated regions would do even better and the absolute size of the estimated externality would be even larger. In other words, the size of the externality shown in Figure 4 is a lower bound.

Notice also that the evidence in Figure 4 only shows the raw differences. A more elaborate diffin-diff analysis, which appropriately controls for observed individual characteristics of job losers, does not change the picture. Overall, the results turn out robust and show up for different outcomevariables (unemployment duration, time between jobs, survivor rates, ...).

Explaining the size of UI market externalities. One important issue is that the size of the externality depends on how strongly the labor market is treated by UI. This depends on the size of the treated group as a fraction of the labor market. For instance, if only a tiny fraction of workers in a labor market becomes eligible to extended UI, we can ignore externalities and the partial equilibrium framework is appropriate. In contrast, if most workers are captured by extended UI, ignoring externalities is problematic.

We can shed light on this issue by estimating how the estimated externality depens on the relative size of the treated group. This can be done in various ways. First, we can take advantage of the fact that REBP districts differ in connectedness with nonREBP regions (as measured the fraction of workers from the control region hired by firms in the treated region). The idea is that local labor markets with many hires from nonREBP regions are less intensely treated by UI extensions, which should translate into weaker externalities. Indeed, we find that market externalities are smaller in more integrated districts. Second, we use as a treatment indicator the fraction of $50+$ workers that qualify for the REBP to split REBP counties into local labor markets with high and low treatment intensity. We find that externalities are twice as large in cells with high treatment intensity. Third, we can look at geographical spillovers. In the baseline results we have excluded unemployed workers living in adjacent nonREBP districts. Workers from these districts are not a valid control group as they are likely affected by spillovers from the REBP region. This offers a further test for externalities of UI extensions: contrasting workers in adjacent districts (who should be affected by REBP due to spillovers) to workers in regions that are more isolated (and who should be unaffected from the REBP). Indeed, we find that UI extensions lead to significantly shorter unemployment durations of unemployed workers in these adjacent districts (compared to less integrated districts). The absolute size of the estimated geographical spillover effect is smaller than the baseline externality, in line with the idea that job search outcomes improve most where competition with REBP workers was strongest.

Another interesting issue is how the estimated externalities vary with labor market tightness. In theory, a weaker labor market is associated with larger search externalities because job rationing 
is more severe. In the extreme, when the number of jobs is fixed, a lower job finding rate of eligible workers would be entirely offset by higher job finding non-eligible workers, keeping employment constant. In general, a reduction in aggregate search effort should therefore have a stronger effect on job finding in a slack than in a tight labor market. Using regional vacancy data to differentiate between more slack and more tight labor markets within the treated regions confirms that, indeed, externalities are stronger in more slack labor markets.

The above effects suggest that search externalities are important. Does this mean wage externalities can be ruled out altogether? Not necessarily, because the estimated externalities are a net effect. Direct identification of wage externalities is more difficult, because not all workers return to the labor market and wage observations are selective. Moreover, a contrast of similar workers in treated and non-treated regions may be contaminated to the extent that wage offers decrease with the duration of unemployment. When we plot post-unemployment wages by age, we see a small spike at age 50 during the program, which does not show up in pre- and post-program times. While this is consistent with a wage externality, it is more likely selectivity (workers with very good wage offers return to the labor market). Regression results do not indicate any significant regional difference in post-unemployment wages, holding the duration of the unemployment spell constant. Overall, the evidence suggests that reemployment wages are unlikely strongly affected by the UI extension.

Policy implications. Our analysis reveals significant market externalities suggesting that the micro effect of extended UI is larger than the macro effect. Quantitatively, our findings indicate that the externality is large, roughly 20 percent of the size of the micro effect. But this means that a micro evaluation that does not take into account variations in labor market conditions overestimates the increase in unemployment resulting from extended UI by as much as 20 percent.

In many instances we are interested in the effect of UI on a labor market where all workers are treated. This raises the question what can be inferred from the Austrian REBP which treated only a subgroup. Compared to a situation where the entire labor market is treated, UI extensions targeted to a subgroup create substitution opportunities. When the eligible group is small and/or the substition elasticity with non-eligible workers is large, labor market tightness will not be strongly affected and market externalities of extended UI will be small. In fact, if the treated group is tiny, we do not need to worry about general equilibrium responses and the partial-equilibrium framework (the micro elasticity) captures the overall effect of the program. Conversely, a UI extension for all workers will likely yield a larger wedge between micro and macro effects than a partial UI extension like the Austrian REBP.

Finally, our results speak to the welfare implications of a UI policy that is more generous in recession (as the current UI system in the US). As suggested by the theroretical work of Landais, Michaillat, and Saez (2010) the Baily formula needs to be extended when externalities are important. They show that, when extended UI increases labor market tightness, extended UI is desirable 
on efficiency grounds. ${ }^{7}$ This is exactly what we found in the context of the Austrian REBP: market externalities are larger the lower initial labor market tightness. Hence our evidence suggests that UI extensions should be extended in bad times.

\section{Program substitution? UI and other benefits}

So far, our analysis has focused on transitions between employment and unemployment. In reality, of course, flows in and out of non-participation are at least as important. Moreover, many non-participants qualify for benefits of other welfare state programs. Since extended UI increases the generosity of UI relative to other programs, flows in (and out) of those other programs may be affected as well, generating fiscal externalities.

To insure against the income loss after UI benefit exhaustion, an unemployed worker may not only search for a new job but also try to get access to other social insurance benefits. "Searching" for other welfare benefits is perhaps particularly relevant for workers with soft disabilities (as musculoskeletal disorders, mental health problems) - for whom working is possible but painful. Moreover, when the DI system grants benefits not solely on the basis of health impairments but also on "vocational factors" related the worker's employability (occupation, age, skills,...), benefit takeup in other programs may be affected more strongly by changes in their relative generosity.

A small but growing literature has studied the impact of UI generosity relative to other programs. Autor and Duggan (2003) argue that long-run increase in the DI caseload observed in the US is partly driven by increases in DI income replacement rates, which were associated with higher labor force exit rates and reduced unemployment rates, particularly for displaced high-school dropouts. Such evidence is not confined to the US. Petrongolo (2009) finds that the UK JSA reform did not only decrease the number of UI benefit recipients, it also increased take-up of DI benefits. Also studies from other countries suggest that program substitution is important. ${ }^{8}$

Early retirement and extended UI. We can again use the Austrian REBP as a quasiexperiment to study the interaction of the UI system with other welfare programs, in particular the DI system (Inderbitzin, Staubli, Zweimüller 2016). As we will see, the REBP triggered not only "program substitution" - lower takeup of DI benefits together with higher UI takeup - but also "program complementarity", a consecutive take-up of UI and DI benefits. Both of these responses are closely related to early retirement choices.

\footnotetext{
${ }^{7}$ Strictly speaking, this proposition holds when unemployment is inefficiently high, i.e. the Hosios condition is violated and a reduction in unemployment increases welfare. This is, of course, what we consider the economically relevant case.

${ }^{8}$ Studies for Sweden (Karlström et al. 2008), the Netherlands (Borghans et al. 2014, Lammers et al. 2013), Finnland (Kyyrä and Ollikainen 2008), and Austria (Staubli, 2011) suggest that program substitution might be quantitatively important. See also the recent US study of Lindner (2016), who finds that higher UI benefits reduce DI application and the effect is quantitatively large. Mueller et al. (2016) and Rothstein and Valetta (2017) do not find any major increase in DI takeup among US worker, who exhausted their UI benefit extensions implemented after the Great Recession.
} 
Figure 5 summarizes the Austrian early-retirement rules for older job losers that prevailed around 1990 and shows how eligibility to the REBP affected these rules. At the time, the regular male retirement age was age $60 .^{9}$ Even without the REBP, existing early retirement provisions allowed older job losers to exit the labor force as early as age 58. To bridge the time until age 60 , when the regular old-age pension could be claimed, a worder aged 58 could draw regular UI benefits for one year and then claim "special income support", a (1-year) pre-retirement benefit for long-term unemployed workers, available from age 59. The REBP made the existing system even more generous. Eligible unemployed entrants could effectively withdraw through the UI system as young as age 55. Notice that the above pathway to retirement relies exclusively on UI, it does not require takeup of DI benefits. Another way of permanently withdrawing from the labor force is early retirement with DI. The DI system in place at the time granted relaxed DI access from age 55 onwards. "Relaxed access" here means that, if an applicant is no longer capable of working in his previous occupation, he is no longer required to take jobs in other occupations. In other words, from age 55 onwards, not only medical but also vocational criteria grant access to a DI pension. ${ }^{10}$

\section{Figure 5}

Incentives. Notice that extended UI and relaxed DI generates incentives that vary by age at job loss. With extended UI, workers above age 55 who would have otherwise retired with DI, can now entirely rely on the UI to bridge the time until the regular retirment age 60 . This program substitution incentive is particularly strong for workers who lose their job between ages 55 and 57 , where retirement without DI is only possible for workers qualifying for extended UI. The incentive to substitute DI in favor of UI is strong for various reasons. First, retirement without DI can be planned with certainty, while early retirement with DI involves a positive probability that a DI application will eventually be rejected and retirement plans do not come true. Second, retirement without DI avoids the hassle of medical checks and bureaucratic hurdles associated with DI take-up. Finally, also financial incentives may induce a worker to substitute DI for UI. While takeup of UI benefits does not necessarily affect the amount of the subsequent public pension, retiring early with DI is typically associated with a permanently lower public pension. ${ }^{11}$

The REBP also created stronger incentives for early retirements associated with DI takeup. This was particularly so for job losers below age 54. As Figure 5 makes clear, even without the REBP a worker could retire early (with DI) when losing the job at age 54, by claiming UI benefits

\footnotetext{
${ }^{9}$ The pension rules at the time gave access to a public pension at age 60 , provided the worker had a continuous work history (at least 35 years of pension contributions). The pension age (and pension rules) have been changed in several successive pension reforms, starting in year 2000.

${ }^{10}$ At the minimum age of relaxed DI access the awards rate of a DI pension increases dramatically (Haller et al. 2017). The minimum age of relaxed access to DI was increased to 57 in 1996, and the 2013 disability reform (IP $\mathrm{Neu}$ implemented a stepwise increase of relaxed access to age 60 by the year 2018. Staubli (2011) and Haller et al. (2017) show that these reforms had a substantial impact on labor supply between ages 55 and 60 .

${ }^{11}$ The pension formula of the DI benefit was the same as for the public pension, with discounts for early retirement. In contrast, drawing the exteded UI benefits did not involve any discounts in the public pension at age 60 . While the DI benefit is based on lifetime earnings (the best 5 years of earnings), the UI benefits is based on earnings of the previous job UI benefits and DI benefits may differ. Workers with a higher UI benefit than the DI benefit, have therefore an additional incentive of substituting DI for UI.
} 
for 12 months followed by a DI pension from age 55. With the introduction of the REBP this option became available to job losers as young as 51. In other words, the REBP rules created program complementarity incentives, i.e. the sequential takeup of extended UI and relaxed DI, particularly for job losers aged 51-53. Notice that also job losers in the control region can exit the labor force at age 54 by drawing the regular UI benefits during the first 52 weeks and followed by relaxed DI (although they cannot rely on extended UI when the DI application is rejected). Therefore, we expect a weaker effect on retirements with DI for job losers aged 54 but strong effects for job losers aged 51-53.

In sum, early retirement incentives are strongest among workers in the age group 51-57. For this age group, we expect more permanent withdrawals from the labor force. However, the early retirement pathways are expected to differ by age of job loss. Due to program complementarity, there should be more early retirements with DI among treated job losers aged 51-53 (with a weaker effect for job losers aged 54). Due to program substitution, there should be less early retirements with DI for job losers aged 55-57.12

Empirical results. To shed light on the relevance of program substitution and program complementarity, we consider a somewhat broader age range as before, focusing on male job losers aged 50-57 with a UI claim between 1985 and 1995. We look only at men because women's the minimum pension age at the time was age 55 coiciding with the age for relaxed access to a DI pension. As a result, incentives for women are quite different and were confined to ages 50-52 only. ${ }^{13}$

Just like before, we drop from the sample job losers who entered unemployment from a job in the steel sector to rule out that worse labor market prospects in treated regions contaminate the results. We also focus on eligible workers and drop non-eligible workers (with less than 15 years of previous experience). ${ }^{14}$ Adopting the same interpretation as in our above analysis of UI search externalities, a comparison of eligible workers between treated and control regions estimates the macro effect of the REBP on early retirement. We also looked at non-eligible workers in treated regions, but could not find significant regional differences in retirement responses for non-eligible workers. This confirms that our above analysis of search externalities works along the intensive margin (shorter unemployment durations for ineligible workers), rather than the extensive margin (fewer labor force withdrawals among this group). Therefore we focus only on eligible workers and their program substitution and complementarity choices to quantify the fiscal externalities

\footnotetext{
${ }^{12}$ In the above discussion we do not consider that all unemployed workers can rely on unemployment assistance (UA) where their regular UI benefits have run out. However, this option is much less attractive. Not only are UA benefits lower that UI benefits, they are also means-tested and associated with a stigma. In the data, we see also responses to extended UI along the UA margin that are relevant for the cost calculation (see below).

${ }^{13}$ For female job losers, the REBP was a pure early retirement program. as many women took advantage of extended UI which ensured a continuous benefit before the public pension could be claimed at age 55 . Female job losers in control regions could retire early already at age 53, claiming one year of regular UI benefits and another year of special income support (that women could get already at age 54). Hence differential incentives exist during ages 50-52. Inderbitzin et al. (2016) show that, indeed early retirements without DI in the age group 50-52 increased very strongly, while there are no such differences from age 53 and higher.

${ }^{14}$ Focusing on eligible workers further implies all workers have a sufficiently long work history which guarantees that they will be eligible for special income support at age 59 and for an old-age pension at age 60.
} 
associated with extended UI.

Figure 6 documents the difference in the incidence of early retirement by age, both in response to introducing the program (the red graph) and to abolishing the program (the blue graph). In Panel A we look at regional differences in the proportion of early retirements after a job loss. The red graph shows that early retirements increased strongly among job losers in response to the introduction of extended UI. The fraction of job losers that eventually retired was up to 20 percentage points higher in REBP regions. Corresponding to incentives, the higher incidence of early retirement is observed in the expected ages (50-57), while there is no difference in early retirements among workers below age 50 and above age 57. Comparing the red and the blue graph reveals further that the effect of terminating extended UI is the mirror image of the effect of introducing it. This implies that, after the program is shut down, regional differences in early retirement after job loss disappear.

It is particularly interesting to explore the extent to which the overall effect on early retirements involves takeup of DI. Panel B of Figure 6 shows that additional early retirements for workers 50-53 are almost entirely associated with DI takeup. This is clear evidence for program complementarity: eligibility for extended UI induces many workers to take up UI and DI benefits sequentially to retire early. Interestingly, the difference in early retirements with DI is insignificant at age 54, consistent with the incentives mentioned above. In contrast, there are fewer early retirements with DI at ages 55-57. While these job losers retire more frequently in treated regions (Panel A), they do not need to claim DI, they just need to stay on UI until retirement. This is clear evidence for program substitution. ${ }^{15}$ Just like for all retirements (Panel A), we also see that regional differences in early retirement with DI are non-existent at ages younger than 50 and they disappear at ages 58 or 59 . The absence of any difference between treated and controls at these ages confirms that differential retirement patterns are indeed driven by extended UI rather than by unobservables contaminating the regional contrast. Similarly, the comparison of the red and the blue graph in Panel B indicates effects of a very similar order of magnitude (with opposite sign) of introducing and terminating extended UI. Regional differences in retirement patterns disappear after the regional extended UI program is abolished.

Total costs and fiscal externalities. Fiscal costs to taxpayers arise because extended UI affects government expenditures not only through higher UI benefit payments and foregone taxes but also because of changed takeup of DI and other programs. Since the ASSD dataset reports takeup of DI and other social insurance benefits, we can estimate the overall fiscal costs of the REBP. This can be done by using the same diff-in-diff framework as before, using as the dependent variable the respective fiscal cost components: foregone taxes, additional UI benefits, and other social insurance benefits. We can calculate the fiscal costs, using the benefit formulas, the earnings history (which enters the benefit formula) and the chosen retirement path. These outcomes are based on observed

\footnotetext{
${ }^{15}$ Conditional on permanently withdrawing from the work force, roughly $2 / 3$ of workers in treated regions retire without DI and $1 / 3$ retire with DI. In control regions, the odds are opposite: roughly $1 / 3$ retire without DI and $2 / 3$ retire with DI. (Control workers, retiring without DI need to rely on unemployment assistance, UA, a means-tested program with lower benefits and the stigma of needing help in a state of emergency, "Notstandshilfe".)
} 
durations for each individual in the various states during ages 50-59 and assume a public pension is drawn between ages 60 and 78 (the average life expectancy of men during that period). Based on this procedure, we estimate the costs to the taxpayer of REBP treatment for job losers in the age group 50-54 to be 13109 Euros per eligible worker. The corresponding cost for treating the age group 55-57 are 9465 Euros per eligible worker aged 55-57.16

Taking into account the interaction of UI benefits with other programs turns out quantitatively important. If we only consider additional UI benefits and foregone taxes but ignoring additional costs (or cost reductions) in other programs, estimated fiscal costs of treating a job loser in the age group 55-57 with extended UI are equal to 15847 Euros. This corresponds to overestimating the fiscal costs by $15847-9465=6382$ Euros or $67(!)$ percent. Interestingly, ignoring fiscal externalities also leads to an overestimation of tax payer costs of REBP treatment also for age group 50-54. While program complementarity increases DI costs substantially, there are cost reductions of oldage benefits (retiring early is associated with a lower pension) and lower cost to the UA program (for the long-term unemployed not eligible to extended UI), which dominate the higher DI costs. Ignoring fiscal externalities, estimated costs are 14417 Euros per eligible job loser aged 50-54. This overestimates fiscal costs by $14417-13109=1308$ Euros or by 10 percent.

The above calculations suggest that total costs of the program are overestimated by 67 percent for job losers aged 55-57 and by 10 percent for job losers aged 50-54. Weighting the two groups as by sample size ( 0.72 for age group $50-54$ and 0.28 for age group $55-57$ ), we estimate the REBP costs neglecting fiscal externalities to be $0.72 \times 14417+0.28 \times 15847=14817$ Euros, while taking fiscal externalities into account as $0.72 \times 13109+0.28 \times 9465=12088$ Euros. Taken together, by ignoring fiscal externalities we overestimate the governments costs of the Austrian REBP by as much as 23 percent.

The more general message is that fiscal externalities may be quantitatively important. Neglecting these costs can lead to a significant and quantitatively large bias in estimating the total costs of more generous UI.

\section{$4 \quad$ UI generosity and job separations}

The existing literature has mainly studied the effect of UI on the job finding rate. We usually assume that changes in UI generosity leave the job separation rate unaffected. The above discussion of market externalities and fiscal externalities has followed this convention. However, it is by no means clear that this assumption holds in reality. It is therefore of interest to take a closer look.

UI and job separations. An older literature has emphasized the importance of UI in long-term employment relationships. In such contracts, firms have an incentive to exploit the UI system for employment adjustments in case of negative demand shocks. The firm offers the workers a job package that includes the wage and a probability of being laid off. With more generous UI

\footnotetext{
${ }^{16}$ For details on the calculation of total additional costs to the government, see Inderbitzin et al. (2016).
} 
firms have an incentive to lay off their workers more frequently, shifting a larger fraction of the workers' compensation to the UI system, thereby generating excessive layoffs. The obvious remedy against such moral hazard behavior on the firm side is experience rating, e.g. a system that makes firms liable for all the costs accruing to the UI system. In reality, however, many UI systems have no experience rating (as in many European countries) and systems where experience rating is incomplete (as in the US). ${ }^{17}$

The argument, originally brought forth by Feldstein (1976), relies on seasonal demand shocks which generate temporary layoffs, though Baily (1977) mentions that similar arguments apply to employment relationships at risk of a permanent layoff. ${ }^{18}$ Hutchens (1999) argues that not only the UI system but also early retirement programs may be part of an implicit contract between firms and workers, with the possibility of a permanent layoffs in case of an adverse shock to the firm. If early retirement rules are very generous (and actuarially unfair), ${ }^{19}$ firms can shift worker compensation partly to early retirement programs generating excess early retirement.

Mortensen and Pissarides (1994) extend the standard DMP model for endogenous job destruction. In this framework, jobs are subject to idiosyncratic shocks and an employment relationship is endogenously terminated as soon as a shock reduces the firm's productivity below a critical level. In such a framework, UI generosity affects layoffs. An increase in UI benefits puts an upward pressure on wages and raises the reservation productivity. Hence there will be more layoffs for a given distribution of idiosyncratic shocks. ${ }^{20}$

While there is an older literature providing evidence for an impact of UI on layoffs, ${ }^{21}$ recent empirical evidence of the effect of UI on the unemployment inflow is scarce. Interestingly, among the few more recent studies is Winter-Ebmer (2003), who provides evidence in the context of the Austrian REBP. He finds that the yearly transition rate from employment to unemployment increased by about 10 percent for workers eligible to the REBP and that this response was concentrated among long-tenured and high-wage blue collar workers. He argues that this evidence is consistent with firms laying off (expensive) workers in long-term contracts. ${ }^{22}$ More recently, Grogger and

\footnotetext{
${ }^{17}$ Layoffs are affected by the marginal implicit tax. The cutoffs of the US experience rating schedule imply that for a large fraction of firms the marginal layoff tax is zero, thus generating excessive layoffs (although the system imposes a positive average layoff tax on firms).

${ }^{18} \mathrm{~A}$ related literature emphasizing implicit contract in the labor market argues that the UI system can be exploited when firms are risk neutral and workers are risk-averse. Unemployment insurance is an important element of the implicit contract and increased generosity of the UI system may increase the incidence of layoffs.

${ }^{19}$ An important element in Hutchens' (1999) model is the fact that early retirement rules are not actuarially fair. A worker retiring one year earlier gets a smaller reduction in benefits than the reduction that would leave social security wealth (the present value of pension benefits) unchanged at given market interest and mortality rates. A higher degree of acturial unfairness makes workers more willing to retire early, which firms can exploit in implicit contracts.

${ }^{20}$ See also the theoretical paper by Mortensen (1990), who studies the role of UI in search and matching model where both inflow into and outflow from unemployment are simultaneously analyzed.

${ }^{21}$ There are several early papers looking at the importance of UI for temporary and permanent layoffs in the US. See Feldstein (1978), Topel (1983), Saffer (1983), Katz and Meyer (1990), Anderson and Meyer (1993).

${ }^{22}$ Winter-Ebmer (2003) uses a 2-percent sample of the ASSD universe covering the period 1986 to 1991 . Because the pre-REBP period covers only one year, it more difficult to disentangle the change in inflow due to UI generosity from the effect of adverse labor market conditions. See also Lalive and Zweimüller (2004b) providing a descriptive analysis of inflow and outflow effects of the REBP and Lalive, van Ours and Zweimüller (2011) examining the effect
} 
Wunsch (2012) study a German UI policy reform that strongly reduced UI benefit duration for older workers. They find a positive "last-minute" increase in the unemployment inflow, suggesting for workers taking advantage of the generous UI rules before they were terminated.

Another reason why UI generosity may affect the unemployment inflow are employment requirements for UI eligibility. Christofides and McKenna (1995), Baker and Rea (1998), and Britto (2015) find that UI rules and UI generosity have a strong impact of employment durations (and the probability of job separation). Christofides and McKenna (1996) find large spikes in job-tounemployment transition rates at the critical employment durations that grant UI eligibility.

REBP effect on transitions from employment to unemployment. We now provide suggestive evidence of a REBP effect on the UI inflow. In Figure 7 we consider individuals who held a job at age 49 and ask whether they still work on the same job at age 55 . Since we can rely on the universe of employees, we can look at a fine grid, month/year of birth. The dashed line shows how intensely a cohort was treated by extended UI. For instance, a worker born in the third quarter of 1938 was already covered by the REBP losing his job at age 50 (in the third quarter of 1988); and was still covered by the REBP when losing the job before turning 55 (in the second quarter of 1993). In contrast, a worker born before July 1933 (after July 1943) was too old (too young) for REBP eligibility when losing the job between ages 50 and 55.

\section{Figure 7}

The red graph in Figure 7 shows the regional difference in the probability that a worker who held a job at age 49 still holds this job at age 55. Cohorts not insured through the REBP during ages 50-54 - either because they were too young or because they were too old - show slightly higher job stability than workers in the control regions. The graph does not only suggest that the REBP had a significant impact, it also suggests that treatment intensity matters a lot: Cohorts continuously insured during ages 50-54 have a substantially higher probability to separate from the job they held at age 49. A possible explanation for this is indeed moral hazard by firms who exploit UI to partly compensate workers in implicit long-term contracts. Notice, however, that the evidence is also consistent with moral hazard by workers deciding voluntarily to quit their job and to take advantage of generous UI (and perhaps exit the labor force). ${ }^{23}$

As mentioned above, existing evidence points to the importance of eligibility requirements as driving the unemployment inflow. The argument is that, when workers pass the eligibility threshold, they are more likely to enter unemployment and take up unemployment benefits. The important eligibility threshold in the Austrian REBP is age. When workers are younger than 50 at the date of job loss, they are eligible to extended UI benefits but job losers younger than 50 are subject to

of UI policy changes on the unemployment inflow using Austrian policy changes.

${ }^{23}$ More precisely, the dashed line shows, for each cohort, the number of months between ages 50:00 (= age 50 years plus 0-1 months) and age 54:11 (= age 50 years plus 11-12 months) at which a worker is insured by the REBP against job loss. Obviously, the indicator ranges from 0 to 60 months. Because employment is measured at quarterly frequency (baseline dates are Feb 15, May 15, Aug 15, Nov 15), while birth cohorts are measured in monthly frequency, small rounding errors may occur for cohorts turning 50 or 55 around the start or termination of the program. 
regular UI benefits (maximum benefits duration of 52 weeks rather than the 209 weeks granted by the REBP). This suggests a discontinuity test for the relevance of miminum eligiblity requirements (Figure 8).

\section{Figure 8}

Panel A of Figure 8 shows the difference in quarterly unemployment inflow rates between treated and control regions before the treatment period (1983-1988). The inflow rates are plotted over the age range 45-55, and age is measured at a fine grid, year-quarter. Before the REBP went into effect, we see only a slight difference across treated and control region and, importantly, we do not see any discontinuity at age 50. Note also that 50-54 years old workers in treated regions have slightly more stable jobs (broadly in line with Figure 7 above).

Panel B of Figure 8 shows the age pattern of job separation rates during the treatment period (1988-1993). Now we see a sharp discontinuity at age 50, suggesting that minimum-age requirement plays a decisive role for the unemployment entry. Notice also that the effect is quantitatively large. The mean of the quarterly job-to-unemployment transition rate was about 2 percent in the pretreatment period and the treatment effect is on the order of magnitude of 1 percent, a 50 percent (!) increase.

Relative importance of inflow- and outflow responses. It is interesting to put the inflow results into perspective by comparing them to unemployment exit rates (Figure 9). First, we plot the exact same graph as in Figure 8, but instead of inflow rates we now plot the quarterly unemployment outflow rates on the vertical axis. Panel A of the figure shows no major differences in outflow rates in the pre-treatment period, while Panel B documents huge increases during the REBP period in the outflow rate for eligible workers in the treated region, that start immediately after age 50, as suggested by the incentives created through the program.

\section{Figure 9}

How important are the responses of outflow rates to more generous UI relative to the responses of the UI inflow? To shed light on this question, let us do the following calculation. Denoting by $i$ the unemployment inflow rate and by $o$ the outflow rate, the steady-state unemployment rate (which balances inflow and outflow) can be written as

$$
u^{*}=\frac{i}{i+o}
$$

Taking the pre-reform means of quarterly inflow and outflow rates, $i=0.02$ and $o=0.53$, the pre-reform steady-state unemployment rate is equal to $u_{0}=0.02 /(0.02+0.53)=3.6 \%$. This may seem low, but corresponds to the low unemployment rates that prevailed also for older workers during the 1980s in Austria. (Here we have to keep in mind that these numbers are calculated from the ASSD excluding steel workers and abstracting from early retirement flows). From Panel $\mathrm{B}$ in Figures 8 we see that the response of the inflow rate to increased UI generosity was roughly 
$\triangle i \approx+0.01$ (1 percentage point), while the average response of the outflow rate was was roughly $\triangle o \approx-0.27$ (27 percentage points). This suggests that, as a consequence of the REBP treatment, the unemployment rate has tripled $u_{1}=0.03 /(0.03+0.26)=10.3 \%$.

The outflow effect can be assessed from the hypothetical unemployment rate that would have emerged due to outflow responses only, keeping the inflow rate at its pre-treatment level. This yields a hypothetical unemployment rate of $u_{1}^{o}=0.02 /(0.02+0.26)=7.1 \%$, while the inflow effect can calculated in an anlogous way, generating a hypothetical unemployment rate of $u_{1}^{i}=$ $0.03 /(0.03+0.53)=5.3 \%$. This increase in the steady-state unemployment rate of $\triangle u \approx 6.7 \%$ can be decomposed into an outflow effect $\triangle u^{o} \approx 3.5 \%$, an inflow effect of $\triangle u^{i} \approx 1.7 \%$ and an interaction effect $\Delta u^{i o} \approx 1.5 \%$. While the outflow effect is clearly the dominant one, it accounts for "only" about 53 percent of the overall increase in unemployment. This is because the inflow effect is substantial, making up roughly 25 percent of the overall increase in the unemployment rate. Moreover, a non-negligible fraction of the predicted increase in the unemployment rate, about 15 percent, is due to the fact the inflow and outflow effect reinforce one another.

Policy implications. The fact that UI has a substantial impact on job separations does not necessarily mean that we should reduce UI generosity. The policy implications depend on the nature of job separations. If generous UI is exploited by firms offering long-term contracts associated with (temporary or permanent) layoffs and early retirements, the obvious remedy to excessive layoffs is an experience-rating system reducing layoff rates to their socially optimal level (Feldstein 1976, Baily 1977, Hutchens 1999). In contrast, if the effect of UI generosity on job separations is because workers quit more frequently, this moral hazard behavior indeed implies that optimal UI should be less generous (Britto 2015).

\section{$5 \quad$ Was the Austrian REBP too generous?}

We have not yet discussed whether implementing the Austrian REBP was an optimal policy, taking into account the various channels through which extended UI affected the labor market. To answer this question we need to adapt an extended optimal benefit formula which takes account of labor market responses - in addition to the lower search effort by eligible workers - which affect costs of the program. The modified benefit formula can be written as (Inderbitzin et al. 2016)

$$
\frac{u^{\prime}(b)-u^{\prime}(w)}{u^{\prime}(w)}=\frac{C_{T}}{C_{M}}-1
$$

where $C_{T}$ are the total fiscal costs and $C_{M}$ the (hypothetical) mechanical costs that would arise in the absence of behavioral responses. ${ }^{24}$ Similar to the Baily-formula, the extended formula implies

\footnotetext{
${ }^{24}$ The hypothetical costs $C_{M}$ can be calculated using the control group as the counterfactual for the behavior of the treated group in the absence of the REBP. Holding labor supply of this group constant, we calculate the difference with and without the REBP. The mechanical costs thus calculate mainly capture the additional costs by providing UI benefits for those who have exhausted UI benefits in the absence of the REBP. The estimated costs are the labor
} 
that optimal UI grants full insurance $b=w$ in the absence of behavioral responses, i.e. when $C_{T}=C_{M}$. Unlike the basic Baily formula, the extended formula takes into account externalities.

Taking the cost estimates presented at the end of section 3 , we have $C_{T}=12087$ Euros and $C_{M}=1713$ Euros, so that the 1.h.s. of the formula is equal to 6.06. Notice that these calculations take externalities into account. Market externalities are captured because $C_{T}$ and $C_{M}$ are calculated from a comparison of treated and control region. This contrast, as we have assumed in Section 2 above, captures the macro effect of UI. Thus $C_{T}$ and $C_{M}$ capture both the micro effect and the market externality. Fiscal externalities are taken into account because the cost calculations include the additional costs (or cost reductions) associated with changes in takeup of other programs. Notice further, that the cost estimates do not take into account additional program costs due to the increased unemployment inflow. Since a higher unemployment incidence generates additional costs to the government, the above estimate of 6.06 for the r.h.s. of the above optimal UI formula should be considered as a lower bound. ${ }^{25}$

To derive an estimate of the insurance value provided by the REBP we proceed in a standard way. We assume that the utility function is CRRA, $u(c)=c^{1-\gamma} /(1-\gamma)$, which allows us to rewrite the 1.h.s. of the above optimal UI formula as $R R^{-\gamma}-1$, where $R R=b /(w-\tau)$ is the UI. Notice that $\mathrm{RR}$ here captures the replacement rate over a 5-year interval, implying $R R=0.42$ of the initial system without the REBP. ${ }^{26}$ We can now calculate the critical degree of risk aversion, $\gamma^{*}$, justifying the implementation of a UI system than is more generous than the pre-REBP system. Under the above assumptions, this implies $\gamma^{*}=2.25$. Because the costs are a lower bound, this estimated value of risk is also a lower bound. This leads us to conclude that the Austrian REBP was too generous.

\section{$6 \quad$ What have we learned?}

Let me conclude. I have discussed several channels through which UI affects the labor market - in addition to the effect of UI on unemployment durations that is commonly emphasized in the literature. I have argued that

- UI generosity may change the labor market equilibrium generating market externalites. The size and direction of these externalities have important implications for the optimal design

market states of To calculate the increase in mechanical costs $M$, we take the labor supply of the control group as a counterfactual for the treatment group in the absence of behavioral responses and calculate the difference in net expenditures with and without the REBP.

${ }^{25}$ Notice that it is not clear how the additional costs arsing from a higher unemployment inflow should be captured in the optimal UI formula. Inefficiently high layoffs do not necessarily imply a less generous UI system, since experience rating may remove the distortion, while additional costs due to higher quits should be considered just like costs arising from longer unemployment durations. In other words, a comprehensive welfare analysis needs to split the inflow effects into quit- and layoff-responses. This is work in progress, see Jäger et al. (2017).

${ }^{26}$ Our calibration takes Austrian UI rules around 1990. Without the REBP, the five-year replacement ratio is based on $1 / 5$ UI benefits and 4/5 unemployment assistance (UA) benefits; with the REBP, we have $4 / 5$ UI benefits and $1 / 5$ UA benefits. We assume a net replacement rate of UI benefits of 55 percent and a net replacement rate of UA benefits of 38.5 percent, or 70 percent of UI benefits. Hence, the five-year net replacement rate of UI benefits without the $\mathrm{REBP}$ is $\mathrm{RR}=1 / 4 \times 0.55+4 / 5 \times 0.385=0.42$. 
of UI policies, including UI generosity over business cycle. In the context of the Austrian REBP, these externalities are negative and quantitatively important, amounting to about 20 percent of the micro effect of extended UI.

- UI is only one among a whole menu of welfare state programs. In the context of the Austrian REBP, we have seen that this creates both program substitution and program complementarity. Detailed calculations of costs to these other programs suggest that overall fiscal externalities are negative and quantitatively large, amounting to more than 20 percent of the costs of UI payments and foregone taxes.

- increasing UI generosity increases job separations and the unemployment inflow, thus generating additional costs to the UI system. Moreover, the inflow effect may be quantitatively large. The Austrian REBP generated an inflow effect accounting for more than 25 percent of the overall increase in unemployment due to extended UI.

As mentioned in the introduction, the above results should be considered as an illustration. They are estimated from a specific program, for a particular group of workers, in a country that has a well developed welfare state. It is not clear, to which extent these results are more generally relevant and externally valid.

While the quantitative effects and the relative importance of the above channels may be very different in other environments and for different groups of workers, I have strong doubts that these channels can be neglected in other contexts. For instance, among the few papers studying UI market externalities is Marinescu (2017), who finds negative market externalities from UI extensions on the US labor market of a similar order of magnitude as those for Austria discussed above. Similarly, Lawson (2015) estimates negative fiscal externalities of UI generosity (via the DI system) for the US, which are substantially larger than those found here. Finally, there is an older empirical literature documenting that UI affects layoffs. While this literature has not been very active recently, I find it hard to believe that this channel is no longer relevant today.

Let me conclude with five more general messages, which I think arise from the research presented above.

1. A clean causal estimate of the unemployment duration elasticity is not enough for policy advice. If market and fiscal externalities, inflow effects and possibly further channels are quantitatively relevant, these responses need to be taken into account when assessing the welfare effect of UI.

2. We need to better understand the general equilibrium effects of UI. Here I confined the analysis to general equilibrium effects that materialize on the labor market through market externalities. But there may be further channels (e.g. the role of UI as an automatic stabilizer over the business cycle), through which UI affects equilibrium outcomes. ${ }^{27}$

\footnotetext{
${ }^{27}$ For interesting recent work in this area, see Di Maggio and Kermani (2016) and Kekre (2017).
} 
3. UI interacts with other welfare state programs. These interactions may be complex. Their importance may vary for different groups in the population; and also across countries due to the large differences in welfare state provisions. It is important to take takeup responses of other welfare state programs into account when evaluating the optimality of an existing UI program.

4. The effect of UI generosity on quits and layoffs is an underresearched topic. Unlike the older UI literature of the 1970s and 1980s, there are only few recent papers studying the impact of UI on the unemployment inflow. However, these responses are potentially important. Moreover, disentangling firm- and worker-driven responses may be important for optimal UI policy.

5. We know very little about firm responses to UI generosity. In particular, we need to better understand how changes in UI generosity affect firms' vacancy postings, hires, layoffs, and wage policies. New data sources (e.g. online job board data and matched firm-worker data linked to vacancy and UI data) can bring new insights into this blank research area.

I think that empirical evidence along the above lines will constitute progress, not only for UI research but for labor market research in general. I am confident we will see interesting work in these areas over the next years. 


\section{References}

Anderson, Patricia M. and Bruce D. Meyer (1993), Unemployment Insurance in the United States: Layoff Incentives and Cross Subsidies, Journal of Labor Economics 11: S70-S95.

Autor, David H., and Mark G. Duggan (2003), The Rise in the Disability Rolls and the Decline in Unemployment, Quarterly Journal of Economics 118: 157-206.

Baily, Martin N. (1977), On the Theory of Layoffs and Unemployment, Econometrica 45: 10431063.

Baily, Martin N. (1978), Some Aspects of Optimal Unemployment Insurance, Journal of Public Economics 10: 379-402.

Baker, M. and Rea, S. A., (1998), Employment spells and unemployment insurance eligibility requirements, Review of Economics and Statistics 80: 80-94.

Barro, Robert (2010), The Folly of Subsidizing Unemployment, Wall Street Journal, August 30 th.

Britto, Diogo G.C. (2015), Unemployment Insurance and the Duration of Employment: Evidence from a Regression Kink Design, Working paper No.1058, University of Bologna.

Borghans, Lex, Anne C. Gielen, and Erzo F. P. Luttmer (2014), Social Support Substitution and the Earnings Rebound: Evidence from a Regression Discontinuity in Disability Insurance Reform, American Economic Journal: Economic Policy 6: 34-70.

Card, David, Raj Chetty and Andrea Weber (2007), Cash-On-Hand and Competing Models of Intertemporal Behavior: New Evidence from the Labor Market, Quarterly Journal of Economics 122: $1511-1560$.

Chetty, Raj (2006), A General Formula for the Optimal Level of Social Insurance, Journal of Public Economics 90: 1879-1901.

Chetty, Raj (2008), Moral Hazard versus Liquidity and Optimal Unemployment Insurance, Journal of Political Economy 116: 173-234.

Christofides, L. N. and C. J. McKenna (1995). Unemployment insurance and moral hazard in employment, Economics Letters 49: 205-210.

Christofides, L. N. and C. J. McKenna (1996). Unemployment insurance and job duration in Canada, Journal of Labor Economics 14: 286-312.

Di Maggio, Marco and Amir Kermani (2016), The Importance of Unemployment Insurance as an Automatic Sabilizer, mimeo, UC Berkeley, 2016.

Feldstein, Martin (1976), Temporary Layoffs in the Theory of Unemployment, Journal of Political Economy 84: 937-958.

Feldstein, Martin (1978), The Effect of Unemployment Insurance on Temporary Layoff Unemployment, American Economic Review 68: 834-846.

Ganong, Peter and Pascal Noel (2017), Consumer Spending During Unemployment: Positive and Normative Implications, mimeo, University of Chicago.

Grogger, Jeffrey and Conny Wunsch (2012), Unemployment Insurance and Departures from Employment: Evidence from a German Reform, mimeo, University of Basel. 
Gruber, Johnathan (1997), The Consumption Smoothing Benefits of Unemployment Insurance, American Economic Review 87: 192-205.

Haller, Andreas, Stefan Staubli and Josef Zweimüller (2017), Self-Screening in Disability Insurance: Evidence from a Discontinuity in Disability Eligibility, mimeo, University of Zurich.

Hamermesh, Daniel S. (1980), Unemployment Insurance and Labor Supply, International Economic Review 21: 517-527.

Hutchens, Robert (1999), Social Security Benefits and Employer Behavior: Evaluating Social Security Early Retirement Benefits as a Form of Unemployment Insurance, International Economic Review 40: 659-678.

Inderbitzin, Lukas, Stefan Staubli and Josef Zweimüller (2016), Extended Unemployment Benefits and Early Retirement: Program Complementarity and Program Substitution, American Economic Journal: Economic Policy 8: 253-288.

Karlström, Anders, Mårten Palme, and Ingemar Svensson (2008), The Employment Effect of Stricter Rules for Eligibility for DI: Evidence from a Natural Experiment in Sweden, Journal of Public Economics 92: 2071-82.

Katz, Lawrence F. and Bruce D. Meyer (1990), Unemployment Insurance, Recall Expectations, and Unemployment Outcomes, Quarterly Journal of Economics 105: 973-1002.

Kekre, Rohan (2017), Unemployment Insurance in Macroeconomic Stabilization, mimeo, University of Chicago.

Kroft, Kory and Matthew Notowidigdo (2016), Should Unemployment Insurance Vary With the Unemployment Rate? Theory and Evidence, Review of Economic Studies 83: 1092-1124.

Krugman, Paul (2013) Unemployment Benefits and Actual Unemployment: An Analogy, New York Times, June 10th.

Kyyrä, Tomi, and Virve Ollikainen (2008), To Search or not to Search? The Effects of UI Benefit Extension for the Older Unemployed, Journal of Public Economics 92: 2048-70.

Jäger, Simon, Benjamin Schoefer, and Josef Zweimüller (2017), UI and the Unemployment Inflow, work in progress.

Lawson, Nicholas (2015), Social Program Substitution and Optimal Policy, Labour Economics 37: $13-27$.

Lalive, Rafael (2008), How do extended benefits affect unemployment duration? A regression discontinuity approach, Journal of Econometrics 142: 785-806.

Lalive, Rafael and Josef Zweimüller (2004a), Benefit Entitlement and Unemployment Duration: The Role of Policy Endogeneity, Journal of Public Economics 88: 2587-2616.

Lalive, Rafael and Josef Zweimüller (2004b), Benefit Entitlement and the Labor Market: Evidence from a Large-Scale Policy Change, in: Labor Market Institutions and Public Policy, Agell, J., M.Keene, and A.Weichenrieder (eds.), Cambridge MA: MIT Press, pp. 63-100.

Lalive, Rafael, Jan van Ours and Josef Zweimüller (2011), Equilibrium Unemployment and the Duration of Unemployment Benefits, Journal of Population Economics 24: 1385-1409.

Lalive, Rafael, Camille Landais and Josef Zweimüller (2015), Market Externalities of Large 
Unemployment Insurance Extension Programs, American Economic Review 105: 3564-3596.

Lammers, Marloes, Hans Bloemen, and Stefan Hochguertel (2013), Job Search Requirements for Older Unemployed: Transitions to Employment, Early Retirement and Disability Benefits, European Economic Review 58: 31-57.

Landais, Camille (2015), Assessing the Welfare Effects of Unemployment Benefits Using the Regression Kink Design, American Economic Journal: Economic Policy 7: 243-278.

Landais, Camille, Pascal Michaillat, and Emmanuel Saez (2017), A Macroeconomic Approach to Optimal Unemployment Insurance: Applications, American Economic Journal: Economic Policy, forthcoming.

Lindner, Stephan (2016), How Do Unemployment Insurance Benefits Affect the Decision to Apply for Social Security Disability Insurance? Journal of Human Resources 51: 62-94.

Ljungqvist, Lars and Thomas J. Sargent (1998), The European Unemployment Dilemma, Journal of Political Economy 106: 514-550.

Ljungqvist, Lars and Thomas J. Sargent (2008), Two Questions about European Unemployment. Econometrica 76: 1-29.

Marinescu, Ioana (2017), The General Equilibrium Impacts of Unemployment Insurance: Evidence from a Large Online Job Board, Journal of Public Economics 150: 14-29.

Michaillat, Pascal (2012), Do Matching Frictions Explain Unemployment? Not in Bad Times, American Economic Review 102: 1721-1750.

Mortensen, Dale T. and Christopher A. Pissarides (1994), Job Creation and Job Destruction in the Theory of Unemployment, Review of Economic Studies 61: 397-415.

Mortensen, Date T. (1990), A Structural Model of Unemployment Insurance Benefit Effects on the Incidence and Duration of Unemployment, Advances in the Theory and Measurement of Unemployment, Yoram Weiss and Gideon Fishelson (eds.), pp 57-81.

Mueller Andreas I., Jesse Rothstein and Till von Wachter (2016), Unemployment Insurance and Disability Insurance in the Great Recession, Journal of Labor Economics 34: 445-475.

Petrongolo, Barbara (2009), The Long-term Effects of Job Search Requirements: Evidence from the UK JSA Reform, Journal of Public Economics 93: 1234-53.

Rothstein, Jesse and Robert G. Valletta (2017), Scraping By: Income and Program Participation After the Loss of Extended Unemployment Benefits, NBER working paper No. 23528.

Saffer, Henry (1983), The Effects of Unemployment Insurance on Temporary and Permanent Layoffs, Review of Economics and Statistics 65: 647-652.

Schmieder, Johannes F., Till von Wachter and Stefan Bender (2016), The Effect of Unemployment Benefits and Nonemployment Durations on Wages, American Economic Review 106: 739-77.

Schmieder, Johannes F. and Till von Wachter (2016), The Effects of Unemployment Insurance: New Evidence and Interpretation, Annual Review of Economics 8: 547-581.

Shimer, Robert (2004), Search Intensity, https://sites.google.com/site/robertshimer/ intensity.pdf.

Staubli, Stefan (2011), The Impact of Stricter Criteria for Disability Insurance on Labor Force 
Participa tion, Journal of Public Economics 95: 1223-35.

Topel, Robert H. (1983), On Layoffs and Unemployment Insurance, American Economic Review 73: 541-559.

Winter-Ebmer, Rudolf (1998), Potential Unemployment Benefit Duration and Spell Length: Lessons from a Quasi-experiment in Austria. Oxford Bulletin of Economics and Statistics 60: $33-46$.

Winter-Ebmer, Rudolf (2003), Benefit Duration and Unemployment Entry: A Quasi-experiment in Austria, European Economic Review 47: 259-273. 
Figure 1: UI and labor market equilibrium in the DMP model

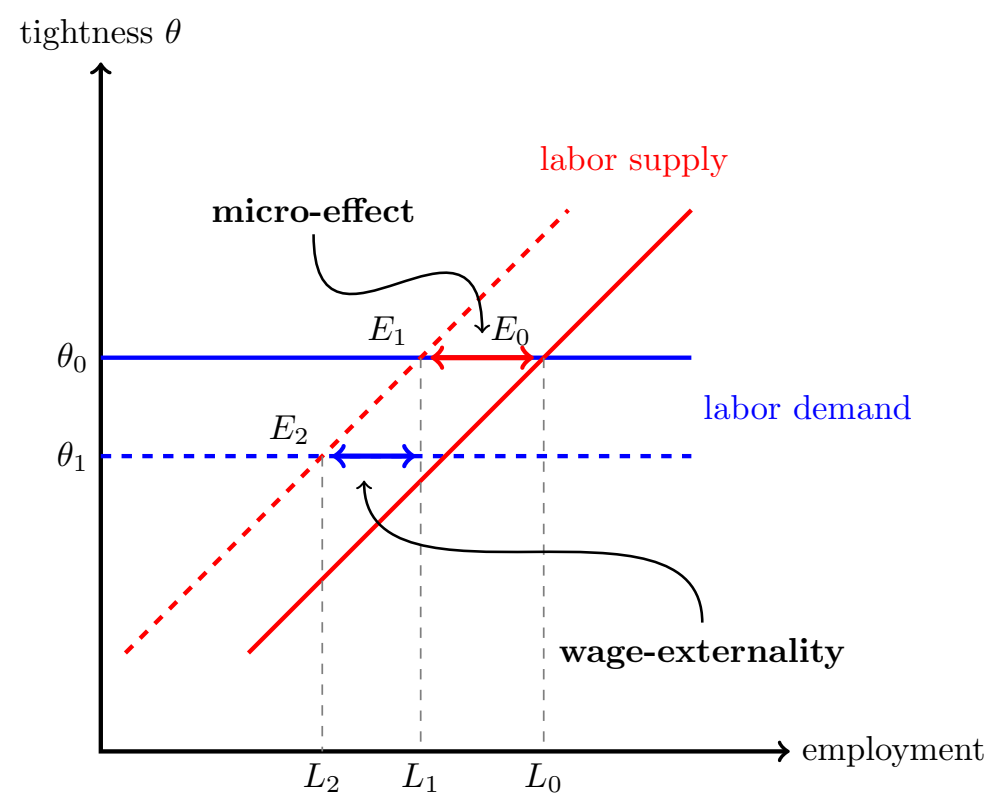

Figure 2: UI and labor market equilibrium with job rationing and rigid wages

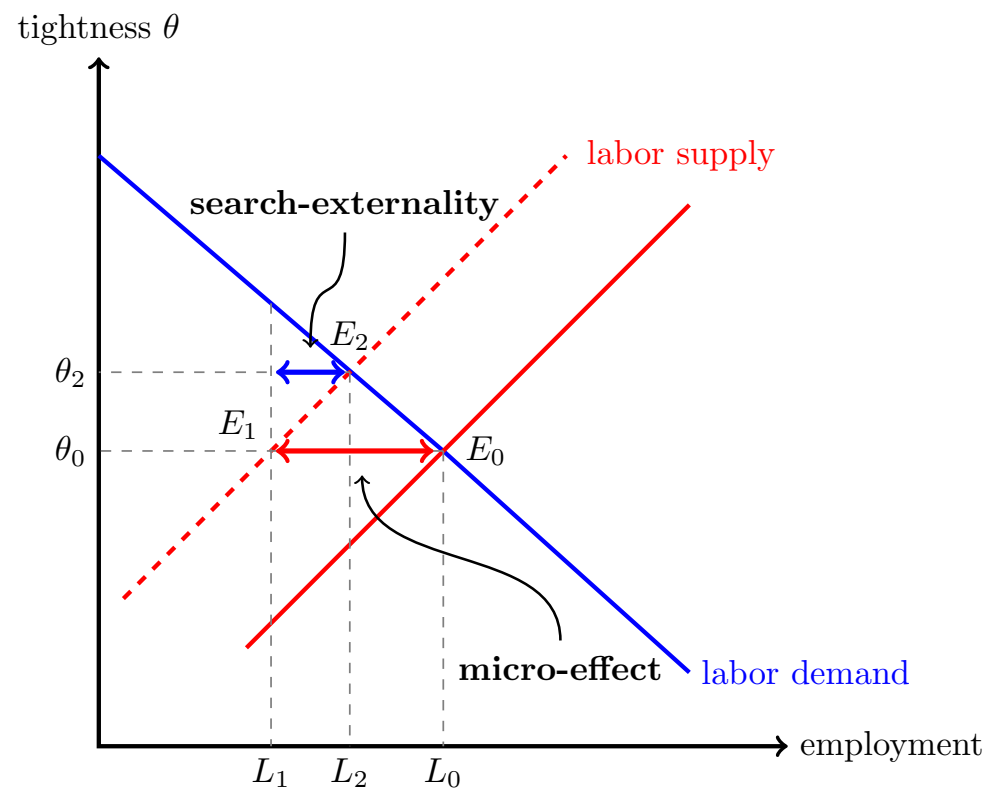


Figure 3: REBP and nonREBP regions in Austria

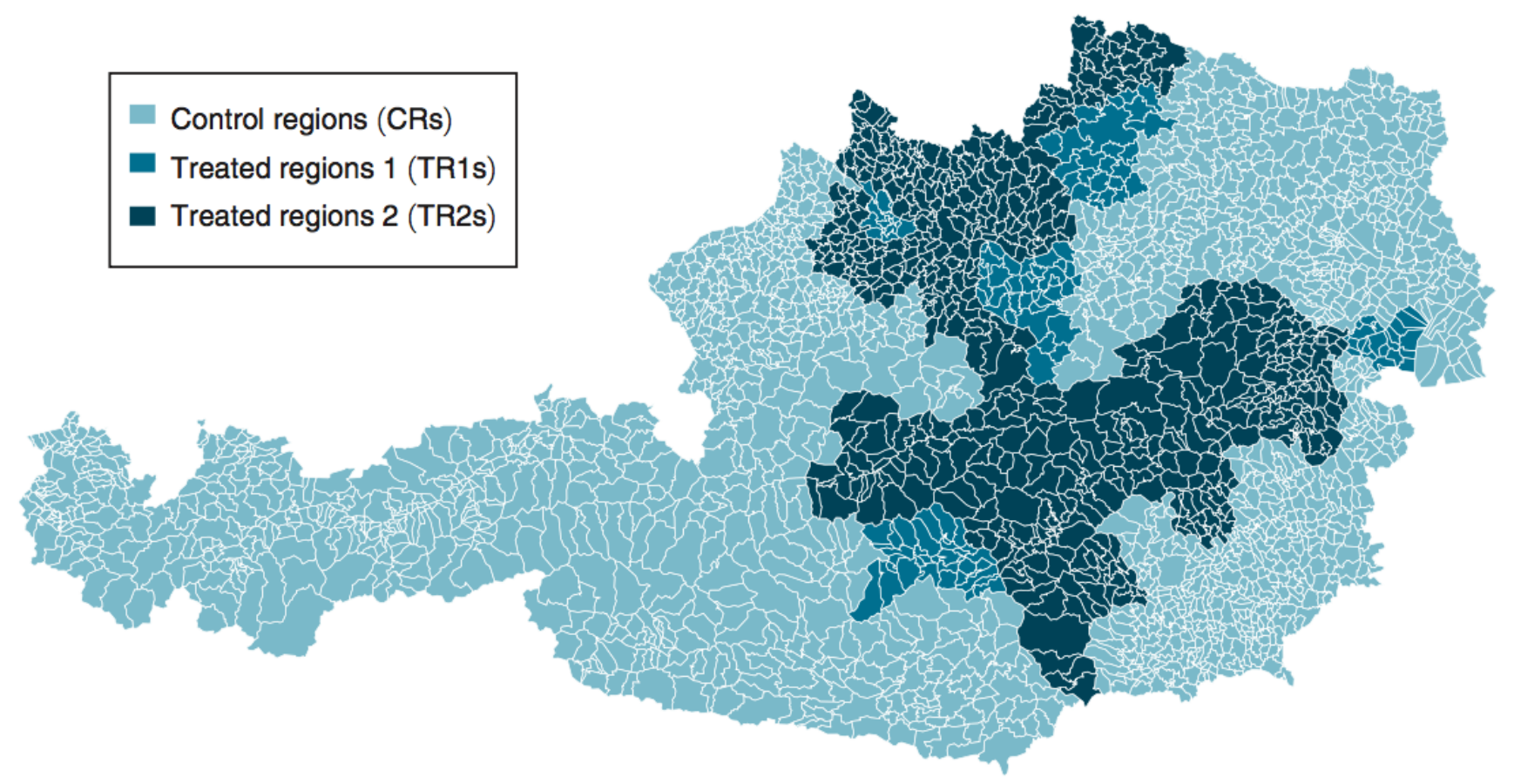


Figure 4: Difference in unemployment durations: REBP versus nonREBP regions

Panel A: Difference in unemployment durations (treated - control), eligible workers

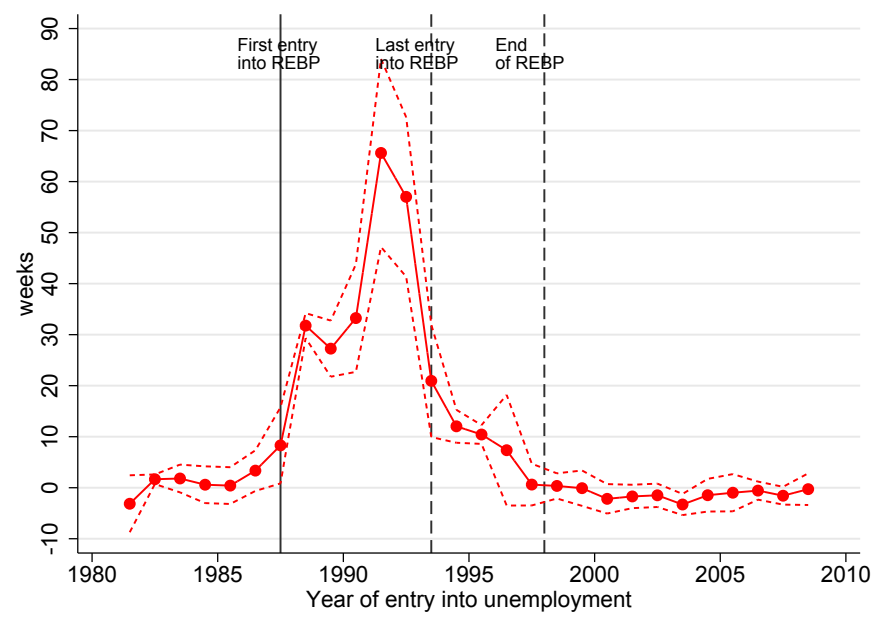

Panel B: Difference in unemployment durations (treated - control), noneligible workers

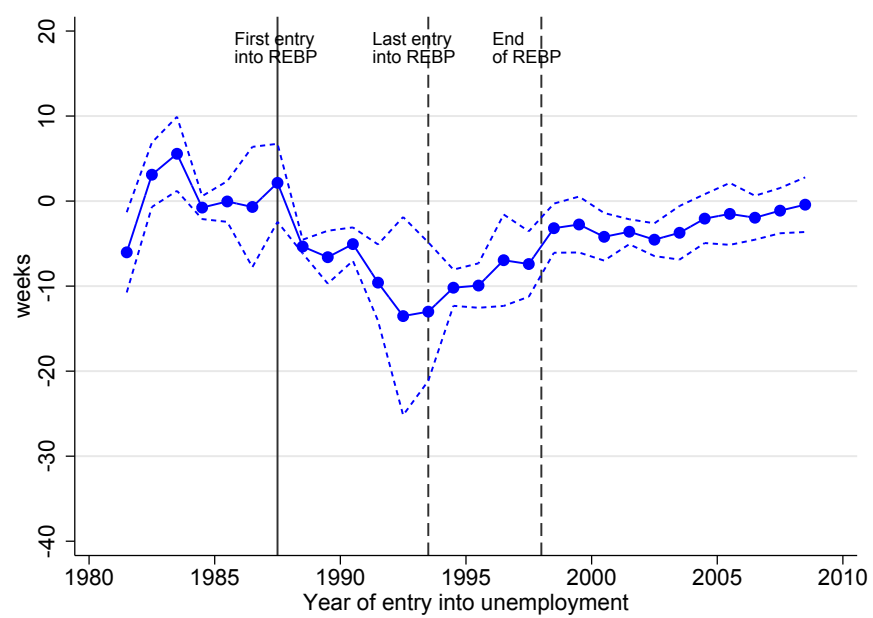

Source: Lalive, Landais, Zweimüller (2015) 
Figure 5: Pathways to retirement

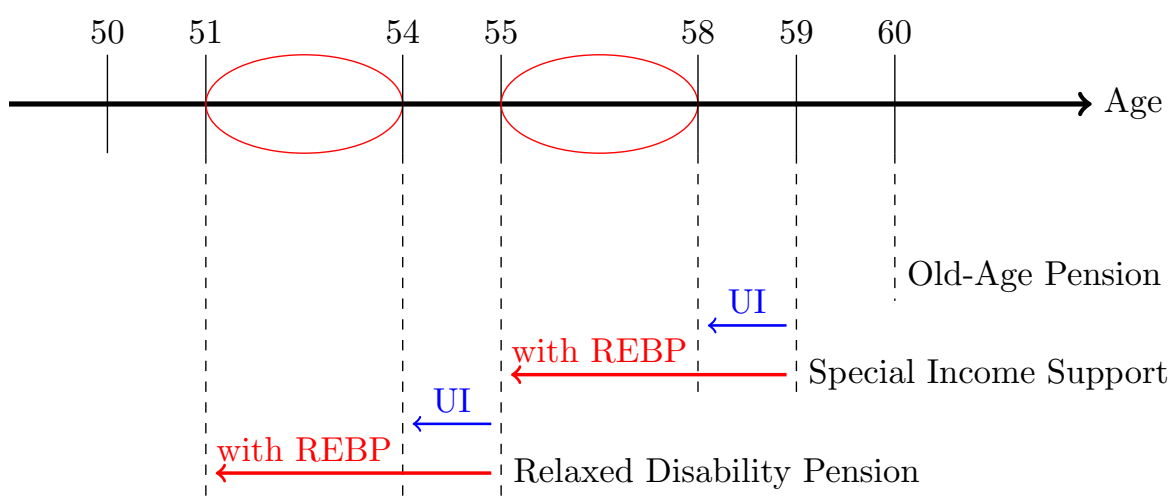

Source: Inderbitzin, Staubli, Zweimüller (2016) 
Figure 6: Early retirement after job loss, by age at unemployment entry

Panel A: Difference in all early retirements (treated - control)

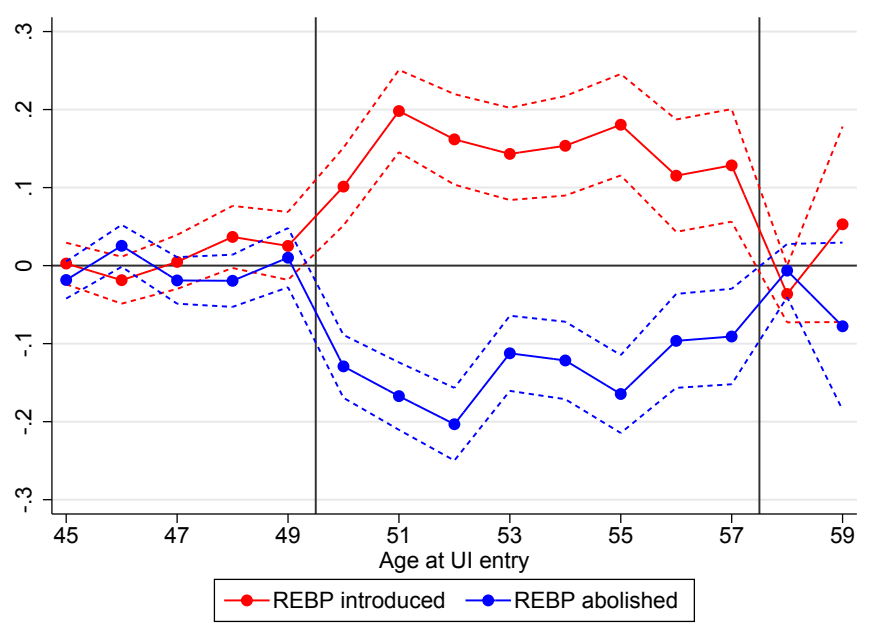

Panel B: Difference in early retirements with DI (treated - control)

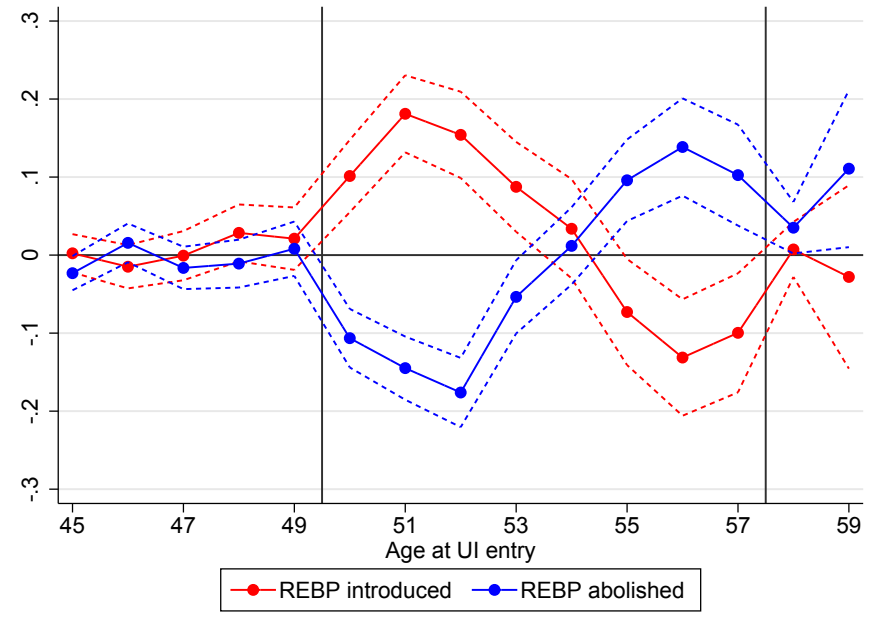

Source: Inderbitzin, Staubli, Zweimüller (2016) 
Figure 7: Same job at age 55 as at age 49? Treated - control regions, by age at job loss

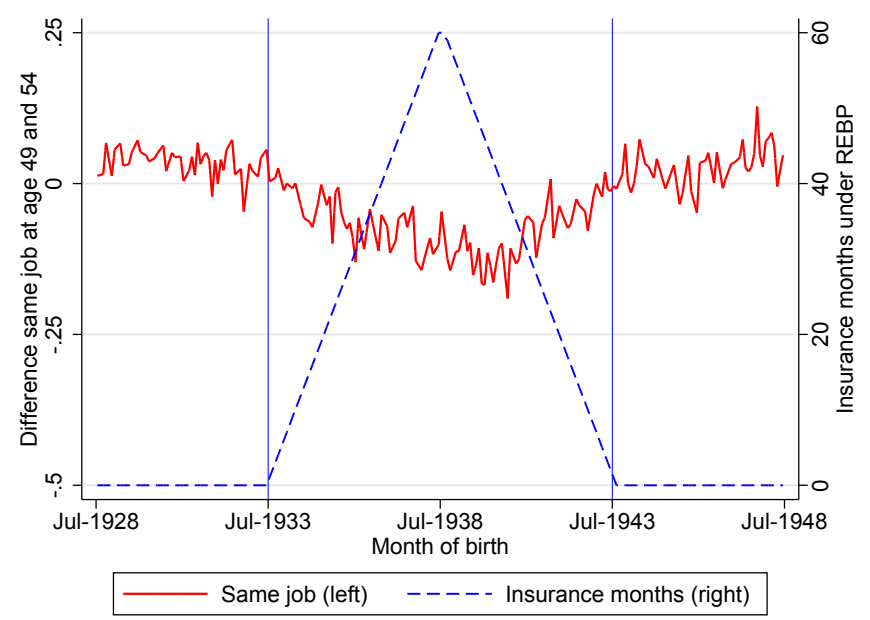


Figure 8: Diff-in-diff estimates of REBP inflow effect, by age at job loss

Panel A: Quarterly inflow rate before REBP (treated - control)

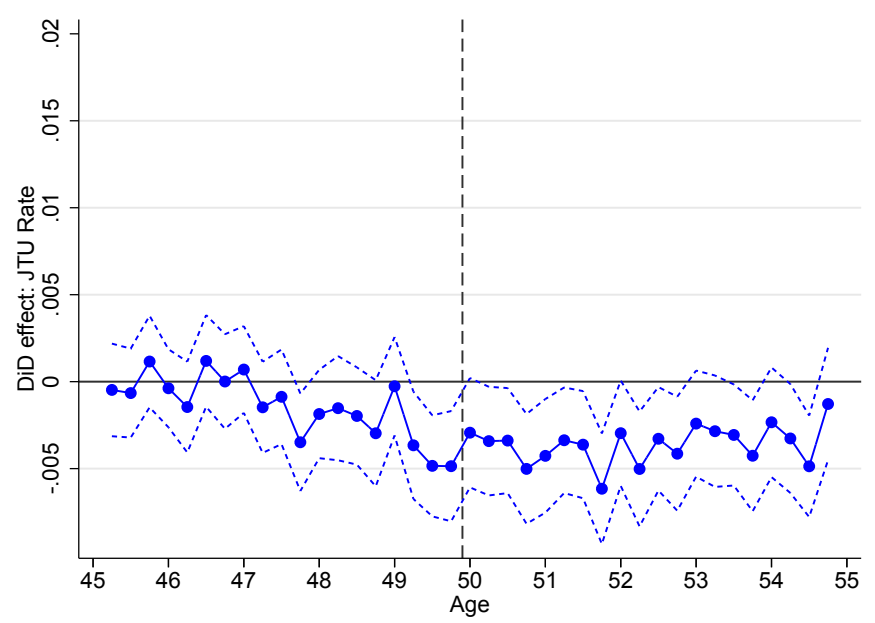

Panel B: Quarterly inflow rate during REBP (treated - control)

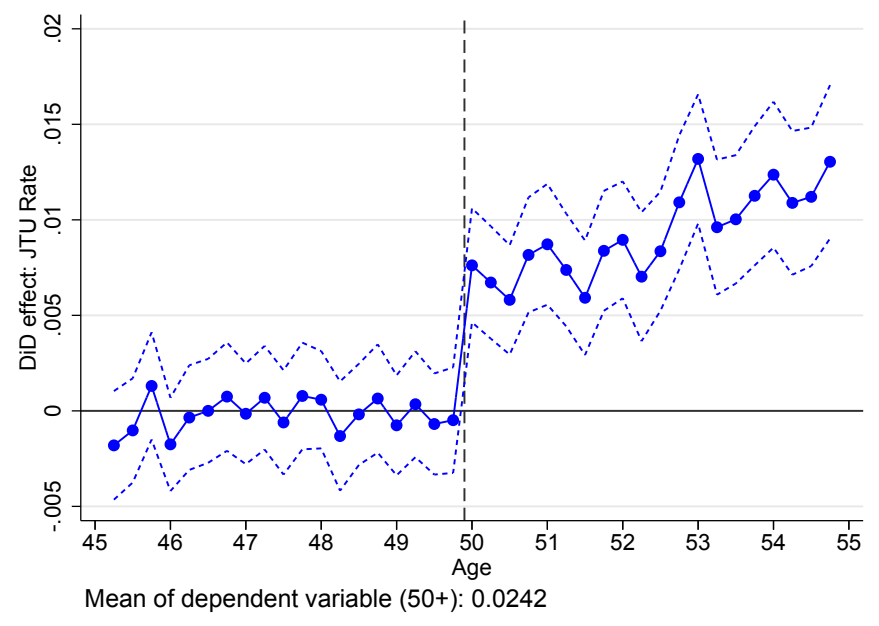


Figure 9: Diff-in-diff estimates of REBP unemployment outflow effect, by age at job loss

Panel A: Quarterly outflow rate before REBP (treated - control)

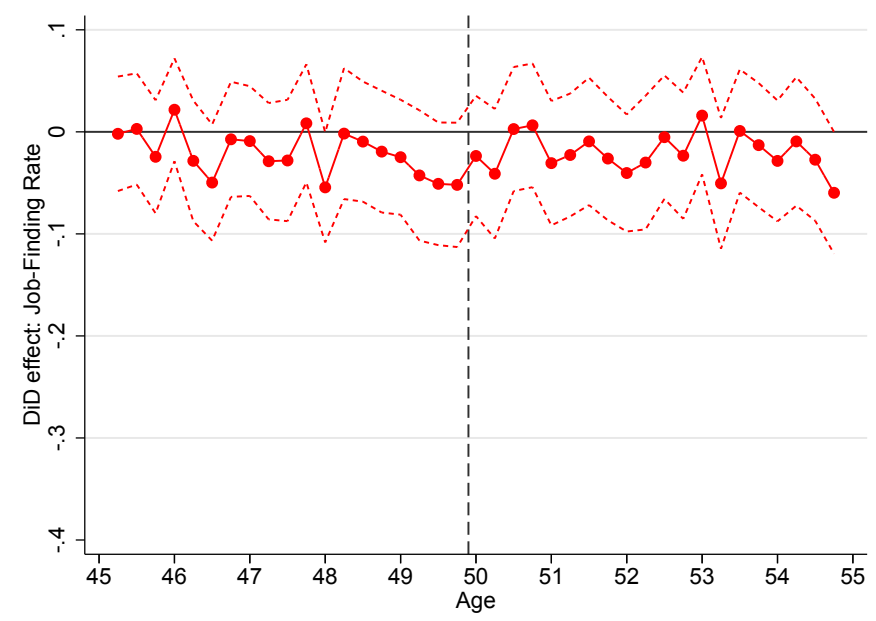

Panel B: Quarterly outflow rate during REBP (treated - control)

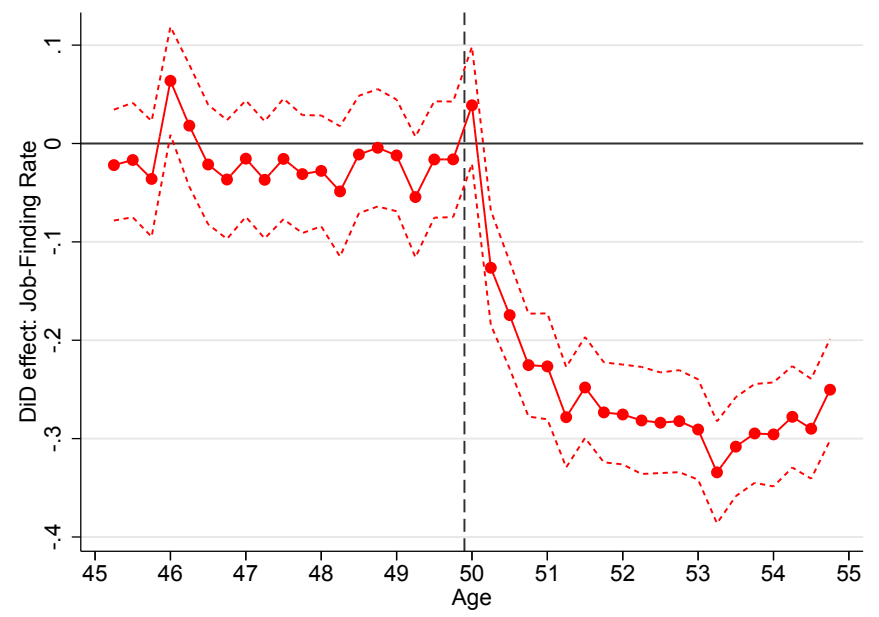

